\title{
Risk factors of sexual dysfunctions in postmenopausal women
}

\author{
Beata Naworska ${ }^{1}$, Monika Bak-Sosnowska ${ }^{2}$ \\ ${ }^{1}$ Department of Perinatology and Oncological Gynecology, School of Health Sciences in Katowice, \\ Medical University of Silesia in Katowice, Poland \\ ${ }^{2}$ Department of Psychology, Chair of Social Sciences and Humanities, School of Health Sciences in Katowice, \\ Medical University of Silesia in Katowice, Poland
}

\begin{abstract}
Objectives: Both somatic and psychosocial factors influence women's sexual functioning. The main objective of the conducted research was to determine the risk factors of sexual dysfunctions in women during the postmenopausal period.

Material and methods: The researcher studied 666 women between the ages of $45-65(M=54.96 \pm 5.42)$, who had their last period no later than 12 months prior. Standardised questionnaires were used to study: sexual functions (FSFI), intensity of menopausal symptoms (KI), level of depression (BDI), body esteem (BES), health behaviours (HBI).

Results: Sexual dysfunctions were diagnosed in $33.03 \%$ of the studied women. The respondents with dysfunctions differed from the respondents without dysfunctions in terms of: age $(p<0.001)$, education $(p<0.001)$, material standing $(p<0.01)$, relationship status $(p<0.001)$, body weight $(p<0.001), B M I(p<0.05)$, self-assessment of health state $(p<0.001)$, presence of chronic diseases $(p<0.05)$, sexual functioning $(p<0.001)$, intensity of menopausal symptoms $(p<0.001)$, level of depression $(p<0.001)$, body self-esteem $(p<0.001)$, health behaviours $(p<0.001)$. Regression analysis demonstrated $(R 2=0.24)$ that the higher the sense of sexual attractiveness, the lower the probability of sexual dysfunctions $(B=-0.13 ; p<0.001)$. In turn, the risk increases with age $(B=0.06 ; p<0.001)$, intensity of menopausal symptoms $(B=0.04 ; p<0.01)$ and concern about one's own body weight $(B=0.04 ; p<0.05)$. Living without a partner (as compared with living in an informal relationship) increases the risk of occurrence of sexual dysfunctions by as much as $129 \%$.

Conclusions: Crucial risk factors of sexual dysfunctions in women during the postmenopausal period include: age, relationship situation, intensity of menopausal symptoms, sense of sexual attractiveness and concern about body weight.

Key words: sexual dysfunctions; postmenopausal; menopausal syndrome; depression; body self-esteem; health behaviours

Ginekologia Polska 2019; 90, 11: 633-639
\end{abstract}

\section{INTRODUCTION}

Sexual dysfunctions in women involve the following aspects: desire, arousal, orgasm and genital-pelvic comfort. Hypoactive sexual desire dysfunction means persistent or remittent lack of sexual thoughts and fantasies. Sexual arousal dysfunction consists in permanent or remittent inability to achieve or sustain sexual arousal during a sexual activity. Orgasmic dysfunction is related to the pace of reaching an orgasm, its frequency or intensity. In turn, Genital-pelvic pain dysfunction concerns the course of sexual intercourse and is related to difficulties in vaginal penetration, hyperactivity of pelvic floor muscles, pain of the vulva and vagina or pelvis, as well as fear of such pain. Diagnosis of sexual dysfunctions takes into account the duration of symptoms (at least 3 months, and in case of genital-pelvic pain at least 1 month), their frequency (at least $3 / 4$ of all sexual experiences) and their onerousness (experiencing subjective distress) [1].

A research conducted in 29 countries on a group of over 27,000 of over 40 years of age demonstrated that the average frequency of occurrence of lack of interest in sex totalled $25.5 \%$, problems with lubrication $-20 \%$, pain during intercourse $-13.5 \%$, and orgasm disorders $-16 \%$ [2]. The most frequent sexual dysfunction in middle-aged women is lack of desire, whose frequency, depending on the research, reaches as much as $98 \%$ [3]. The presence of sexual dysfunctions in the menopausal period is connected with lower emotional satisfaction and life satisfaction, poor self-image as well as with higher onerousness of symptoms of the menopausal syndrome $[4,5]$. 
Metanalyses point to a number of factors that are incontestably conducive to the occurrence of sexual dysfunctions in women at this stage of life. These include both physical factors (age, oestrogen deficiency, menopause type, chronic medical problems, partner's sexual problems, intensity of menopausal symptoms) and psychosocial ones (smoking tobacco, drinking alcohol, quality of relationship with the partner, separation, divorce or partner's death, level of sexual knowledge, access to healthcare, attitude towards one's health, psychological problems, depression, anxiety, body image). As far as other factors are concerned, conclusions are not unequivocal, sometimes even inconsistent. It concerns, i.a.: level of androgens, use of hormonal therapy, obstetric history, physical activity, education, practised profession, socio-economic status, duration of relationship, frequency of sexual intercourses [3,6-10].

Many factors that have potential or actual influence on the development of sexual dysfunctions in women are interrelated. For example, it is known that changes connected with ageing and increase in body weight, which is frequent in the menopausal period, have a negative influence on women's body self-image, which can, in turn, favour the development of depressive disorders. Also, there is a negative correlation between the occurrence of depression and health-promoting behaviours, such as physical activity or health prophylaxis, and a positive correlation between the occurrence of depression and increase in the intensity of symptoms of menopausal syndrome. Concurrently, increased accidental symptoms of menopause favour the development of depression [11-15]. In the Pubmed base, which covers the years 2000-2019, there have been no reports found that would analyse cumulatively the influence of the aforementioned variables on the risk of development of sexual dysfunctions. Due to the above, the first objective of the authors' own research was to evaluate the relations between the occurrence of sexual dysfunctions in women in the postmenopausal period and: intensity of menopausal symptoms, efficiency of determined sexual functions, level of depression, body self-esteem, health behaviours. The final objective of the research was to determine the risk factors of sexual dysfunctions in the studied group.

\section{MATERIAL AND METHODS}

\section{Participants}

The research involved women in the postmenopausal period, patients of Primary Healthcare Centers (PHC) in the territory of Silesia (Poland). Random selection was used. Participation in the study was offered to all PHC patients reporting to the centres between November 2018 and March 2019 and meeting the following criteria of inclusion in the research: age between 45 and 65 years, the last period at least 12 months prior to the participation in the research, agreement to participate in the research. The following constituted exclusion criteria: health state preclusive of participation in the research, withdrawal of consent to participate in the research, diagnosed: psychosis, anxiety disorders, functional and/or secondary hyperprolactinaemia (e.g. associated with drugs such as selected neuroleptics, antidepressants, and spironolactone or associated with improper thyroid function or pituitary adenoma), < 1 year after cardiac infarction and cerebral vascular accident, neoplastic disease, intellectual disability. The questionnaires were filled in by 688 persons, including 22 that were incomplete. Ultimately, results of 666 women were included in the research.

\section{Methods}

The diagnostic poll method was employed, with the use of the following questionnaires:

- Female Sexual Function Index (FSFI) for the study of sexual dysfunctions; it includes 19 items in 6 subscales: Desire, Arousal, Lubrication, Orgasm, Satisfaction, lack of Pain; the respondent determines the intensity or frequency of each sexual function; the answers are correspondingly awarded points and multiplied by a determined numerical index; dysfunction is recognised at the value of $\leq 3.9$ point for each subscale and $\leq 26.55$ points for the general score;

- Kupperman Index (KI) for the assessment of quality and level of intensity of menopausal symptoms; it includes 11 categories: Sweating and hot flashes, Paraesthesia, Insomnia, Nervousness, Melancholia, Vertigo, Weakness (fatigue), Arthralgia and myalgia, Headache, Heart palpitations, Formication; the respondent determines the intensity of symptoms on a scale; the answers are awarded points and their sum allows for a diagnosis of lack of menopausal syndrome ( $\leq 20 \mathrm{pts}$ ) or intensity thereof: light (21-25 pts), moderate (26-30 pts), severe (> 30 pts);

- Beck Depression Inventory (BDI) for the study of depressive disorders; it includes 21 items; the respondent chooses one of four answers, adequate to the intensity of the described symptoms; the sum of points allows to ascertain lack of depression ( $<9$ pts) or its intensity: light (10-18 pts), moderate (19-29 pts), severe (> 30 pts);

- Body Esteem Scale (BES) for body esteem; it includes 35 items that evaluate parts or functions of the human body, grouped into 3 categories: Sexual attractiveness, Weight concern, Physical condition; the respondent takes a stance on each item, marking an appropriate number on a scale from 1 (decidedly negative) to 5 (decidedly positive);

- Health Behaviour Inventory for the assessment of health behaviours; it includes 24 statements grouped into 
4 categories: Eating habits, Prophylaxis, Positive attitude, Health practices; the respondent determines the frequency of each behaviour on a scale from 1 (nearly never) to 4 (nearly always); the general score is the measure of intensity of health behaviours;

- Respondent's particulars including questions concerning sociodemographic data and data connected with state of health.

Participation in the research was voluntary and anonymous. The respondents did not obtain any remuneration for it, they answered the questions included in the questionnaires individually and on their own and the time they were given for providing the answers was not limited.

\section{Statistical analysis and Ethical Implications}

Statistical analyses were carried out with the use of the IBM SPSS Statistics 25 package. Qualitative and quantitative analyses were conducted, including logistic regression analysis. The assumed significance level equalled $a=0.05$. The research obtained a positive opinion from the Bioethical Commission at the Medical University of Silesia in Katowice (KNW/0022/K/10/18).

\section{RESULTS}

The average age of respondents equalled $55.23 \pm$ \pm 6.15 years, the average age of the last period equalled $49.01 \pm 3.74$ years. The majority of respondents had secondary (53.39\%) or higher education (32.68\%), lived in the city $(79.52 \%)$, lived in a relationship (85.04\%), had children (89.86\%). Details concerning the results obtained by the studied persons within the scope of the remaining analysed variables are presented below (Tab. 1).

The analysis demonstrated that $33.03 \%$ of the studied group meets the diagnostic criteria of sexual dysfunctions. The respondents with sexual dysfunctions, as compared to the respondents without this type of dysfunctions: were older $(U=34714.5 ; p<0.001)$, significantly more frequently had primary and vocational education, and significantly less frequently had higher education $\left[x^{2}(3)=24.74\right.$; $p<0.001$ ], significantly less frequently assessed their material standing as very good ( $p=0.004 ; V=0.14)$, significantly more frequently did not have a partner and significantly less frequently lived in either a formal or informal relationship $\left[x^{2}(2)=53.97 ; p<0.001\right]$, had significantly higher body weight $(U=41515 ; p=0.032)$ and $B M I(U=40099.0 ; p<0.05)$,

Table 1. Descriptive statistics of variables analysed in the studied group

\begin{tabular}{|c|c|c|c|c|c|c|}
\hline & $\mathbf{n}$ & M & Me & SD & Min. & Max. \\
\hline Current age [years] & 665 & 54.96 & 54.00 & 5.42 & 45.00 & 65.00 \\
\hline Age of last period [years] & 666 & 49.06 & 49.00 & 3.55 & 39.00 & 60.00 \\
\hline Height [centimeters] & 666 & 163.97 & 164.00 & 5.48 & 150.00 & 182.00 \\
\hline Weight [kilograms] & 666 & 72.03 & 70.00 & 12.06 & 43.00 & 164.00 \\
\hline BMI $\left[\mathrm{kg} / \mathrm{m}^{2}\right]$ & 666 & 26.81 & 26.50 & 4.47 & 17.22 & 64.06 \\
\hline Lenght of the relationship with the partner [years] & 592 & 26.24 & 28.00 & 11.18 & 0.00 & 55.00 \\
\hline FSFI - Total score & 666 & 28.71 & 30.20 & 9.96 & 2.20 & 45.00 \\
\hline FSFI — Desire & 666 & 2.97 & 3.00 & 1.19 & 0.60 & 6.00 \\
\hline FSFI - Arousal & 666 & 3.34 & 3.60 & 1.59 & -0.30 & 6.00 \\
\hline FSFI — Lubrication & 666 & 3.89 & 4.20 & 1.76 & 0.00 & 6.00 \\
\hline FSFI — Orgasm & 666 & 3.79 & 4.00 & 1.72 & 0.00 & 6.00 \\
\hline FSFI - Satisfaction & 666 & 4.21 & 4.40 & 1.24 & 0.40 & 6.00 \\
\hline FSFI — lack of Pain & 666 & 4.19 & 4.40 & 1.67 & 0.00 & 6.00 \\
\hline $\mathrm{KI}$ - Total score & 666 & 18.41 & 18.00 & 9.47 & 0.00 & 51.00 \\
\hline BDI - Total score & 666 & 11.81 & 10.00 & 8.95 & 0.00 & 63.00 \\
\hline BES - Sexual attractiveness & 666 & 45.38 & 45.00 & 9.37 & 16.00 & 65.00 \\
\hline BES - Weight concern & 666 & 31.56 & 32.00 & 9.01 & 10.00 & 50.00 \\
\hline BES - Physical condition & 666 & 30.66 & 31.00 & 7.26 & 9.00 & 45.00 \\
\hline IZZ - Total score & 666 & 78.60 & 79.00 & 15.01 & 29.00 & 120.00 \\
\hline IZZ - Eating habits & 666 & 19.79 & 20.00 & 4.79 & 7.00 & 30.00 \\
\hline IZZ — Prophylaxis & 666 & 20.06 & 20.00 & 4.79 & 6.00 & 31.00 \\
\hline IZZ - Positive attitude & 666 & 20.16 & 20.00 & 4.23 & 5.00 & 30.00 \\
\hline IZZ - Health practices & 666 & 18.59 & 19.00 & 4.20 & 6.00 & 30.00 \\
\hline
\end{tabular}

$\mathrm{M}$ - average; $\mathrm{Me}$ - median; SD — standard deviation 
significantly less frequently assessed their state of health as very good or good and significantly less frequently as average $(p<0.001 ; V=0.20)$, significantly more frequently suffered from chronic diseases $\left[x^{2}(1)=5.56 ; p=0.018\right]$.

It was also demonstrated that the respondents with sexual dysfunctions differed from the respondents without such dysfunctions within the scope of all the variables assessed with the use of standardised questionnaires, which was presented in Table 2.

Because the concern about one's body weight was the only variable that achieved a higher level in the respondents without sexual dysfunction, an analysis of the relations of that variable with the declared body weight of the respondents was conducted. A negative correlation was demonstrated ( $r$ o $=-0.35 ; p<0.001$ ).

The analysis of dependence between the studied variables demonstrated that the scales of sexual functions are positively related at a level ranging from moderate to strong. Additionally, all the dimensions of sexual functions are positively related at a level ranging from weak to moderate with the dimensions of body self-esteem and health behaviours. Moderate and negative correlations appear between depressive symptoms and sexual functions, which means that the higher the level of depression, the lower the level of sexual functions. Details concerning the dependence between the studied variables are presented in the table below (Tab. 3).

In order to establish the factors determining the occurrence of sexual dysfunctions, a logistic regression analysis was conducted with the use of the progressive selection method which included the use of the likelihood ratio method. The assumed model proved to be well adjusted to the gathered data, which is demonstrated by the Hosmer-Lemeshow test $\left[X^{2}(8)=9.02 ; p=0.341\right]$. This model explains $24.2 \%$ of variability of sexual dysfunctions (Cox and Snell's $R^{2}=0.242$; Nagelkerke's $R^{2}=0.341$ ). The regression indicator for the final model was included in Table 4.

Only for the sense of attractiveness is the direction of dependence negative, which means that the higher the level of sexual attractiveness, the lower the probability of sexual dysfunctions (with each unit in the result of the BES questionnaire by $13 \%$ ). The risk of occurrence of sexual dysfunctions increases by $4 \%$ with the increase in intensity of menopausal symptoms (by 1 unit in the result of the $\mathrm{KI}$ questionnaire) and concern about weight (by 1 unit in the result of the BES questionnaire). The risk of dysfunctions

Table 2. Comparison of respondents with sexual dysfunctions with respondents without sexual dysfunctions in terms of sexual functions, intensity of menopausal symptoms, level of depression, body self-esteem and health behaviors

\begin{tabular}{|c|c|c|c|c|c|c|c|c|c|}
\hline & \multicolumn{3}{|c|}{ No dysfunction } & \multicolumn{3}{|c|}{ Dysfunction } & \multirow{2}{*}{$\mathbf{U}$} & \multirow{2}{*}{$\mathbf{p}$} & \multirow{2}{*}{$\eta^{2}$} \\
\hline & M & Me & SD & $M$ & $\mathrm{Me}$ & SD & & & \\
\hline \multicolumn{10}{|l|}{ Sexual functions (FSFI) } \\
\hline Desire & 3.42 & 3.62 & 1.04 & 1.96 & 1.89 & 0.80 & 12850.5 & $<0.001$ & 0.35 \\
\hline Arousal & 4.13 & 4.21 & 0.94 & 1.55 & 1.57 & 1.28 & 5100.5 & $<0.001$ & 0.51 \\
\hline Lubrication & 4.74 & 4.85 & 0.90 & 1.94 & 2.42 & 1.69 & 5752.5 & $<0.001$ & 0.49 \\
\hline Orgasm & 4.63 & 4.84 & 0.88 & 1.87 & 2.40 & 1.63 & 5666.0 & $<0.001$ & 0.50 \\
\hline Satisfaction & 4.77 & 4.83 & 0.83 & 2.91 & 3.21 & 1.04 & 7805.5 & $<0.001$ & 0.45 \\
\hline Lack of Pain & 5.35 & 5.60 & 0.79 & 3.61 & 4.00 & 1.69 & 14526.0 & $<0.001$ & 0.31 \\
\hline Intensity of menopausal symptoms (KI) & 17.06 & 17.08 & 9.11 & 21.48 & 21.0 & 9.59 & 34760.0 & $<0.001$ & 0.04 \\
\hline Level of depression (BDI) & 9.93 & 8.05 & 7.54 & 16.08 & 14.05 & 10.36 & 29319.5 & $<0.001$ & 0.09 \\
\hline \multicolumn{10}{|l|}{ Body self-esteem (BES) } \\
\hline Sexual attractiveness & 48.00 & 48.0 & 8.33 & 39.41 & 39.0 & 8.89 & 22221.5 & $<0.001$ & 0.18 \\
\hline Weight concern & 33.11 & 34.0 & 8.73 & 28.03 & 29.0 & 8.66 & 31491.5 & $<0.001$ & 0.07 \\
\hline Physical condition & 32.21 & 33.0 & 6.59 & 27.12 & 27.0 & 7.47 & 28776.5 & $<0.001$ & 0.10 \\
\hline \multicolumn{10}{|l|}{ Health behaviours (IZZ) } \\
\hline Total score & 80.33 & 81.0 & 14.00 & 74.66 & 74.0 & 16.45 & 37111.5 & $<0.001$ & 0.03 \\
\hline Eating habits & 20.27 & 20.0 & 4.57 & 18.70 & 19.0 & 5.10 & 39101.5 & 0.001 & 0.02 \\
\hline Prophylaxis & 20.52 & 21.0 & 4.60 & 19.02 & 19.0 & 5.05 & 38845.0 & $<0.001$ & 0.02 \\
\hline Positive attitude & 20.73 & 21.0 & 4.01 & 18.84 & 19.0 & 4.43 & 35477.5 & $<0.001$ & 0.04 \\
\hline Health practices & 18.81 & 19.0 & 4.05 & 18.09 & 18.0 & 4.49 & 42275.5 & 0.038 & 0.01 \\
\hline
\end{tabular}

U - Mann-Whitney test result; $\mathrm{p}$ - significance level; $\eta 2$ - effect size 


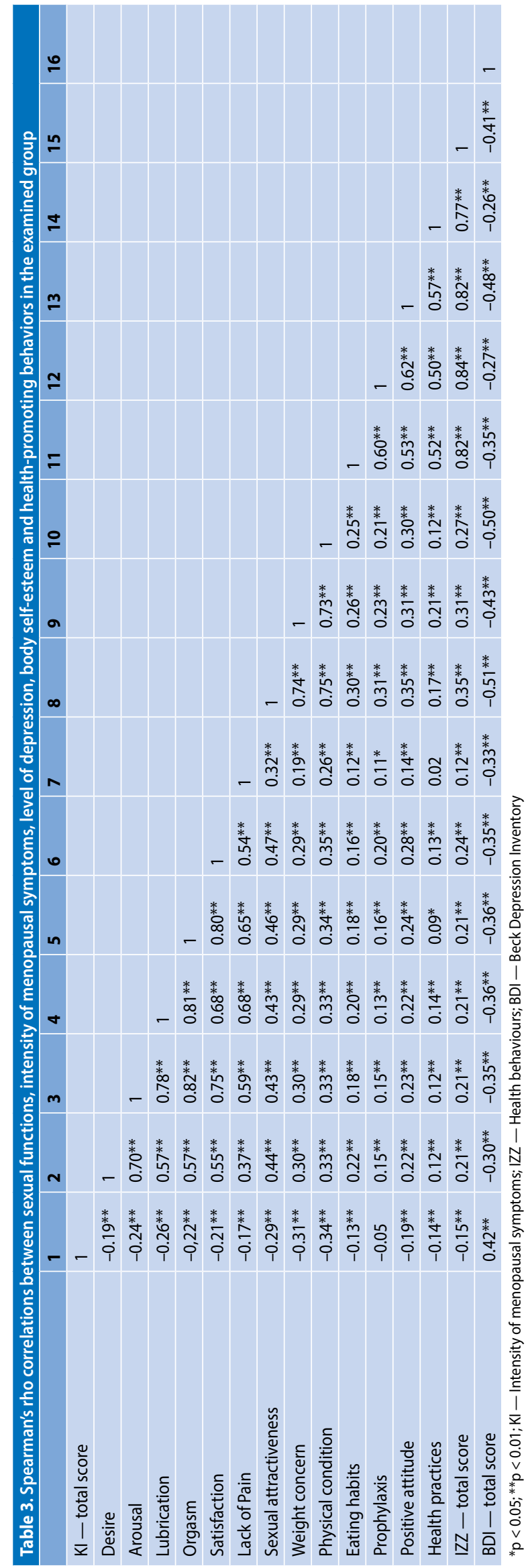

\begin{tabular}{|c|c|c|c|c|c|}
\hline & B & SE & Z & p & $\begin{array}{l}\text { Exp (B), } \\
(95 \% \mathrm{Cl})\end{array}$ \\
\hline Current age & 0.06 & 0.02 & 12.36 & $<0.001$ & $\begin{array}{l}1.06 \\
(1.03-1.10)\end{array}$ \\
\hline Partnership status & & & 21.88 & $<0.001$ & \\
\hline Partnership status (1) & 1.29 & 0.28 & 21.36 & $<0.001$ & $\begin{array}{l}3.62 \\
(2.10-6.24)\end{array}$ \\
\hline Partnership status (2) & 0.02 & 0.31 & 0.00 & 0.957 & $\begin{array}{l}1.02 \\
(0.55-1.88)\end{array}$ \\
\hline $\mathrm{KI}$-total score & 0.04 & 0.01 & 10.40 & 0.001 & $\begin{array}{l}1.04 \\
(1.02-1.06)\end{array}$ \\
\hline $\begin{array}{l}\text { Sexual } \\
\text { attractiveness }\end{array}$ & -0.13 & 0.02 & 52.16 & $<0.001$ & $\begin{array}{l}0.88 \\
(0.85-0.91)\end{array}$ \\
\hline Weight concern & 0.04 & 0.02 & 5.58 & 0.018 & $\begin{array}{l}1.04 \\
(1.01-1.08)\end{array}$ \\
\hline Constant & -0.59 & 1.16 & 0.26 & 0.610 & 0.55 \\
\hline
\end{tabular}

B - standardized regression coefficient; SE — standard error; Z — Wald test result; $\mathrm{p}$ - significance level; $\operatorname{EXP}(\mathrm{B})$ - odds ratio; $\mathrm{Cl}$ - confidence interval; (1) - no partner compared to the informal relationship; (2) - formal relationship compared to informal relationship

increases by $6 \%$ with age (per 1 year). Lack of partner (as compared with living in an informal relationship) increases the risk of occurrence of sexual dysfunctions by as much as $129 \%$ and, thereby, this condition is the strongest determinant of sexual dysfunctions in the assumed model.

\section{DISCUSSION}

Women's sexual functioning in the postmenopausal period can be subject to significant changes in comparison with the previous period, among other things due to the physiological processes connected with the termination of the reproductive activity and their psychological consequences. It is also a time of increased vulnerability to different kinds of disorders in sexual and emotional life. It is estimated that while in the general population sexual dysfunctions afflict between 25 and $63 \%$ of women, in the population of middle-aged and elderly women their frequency equals over 50\% [16]. In the author's own research, the criteria of sexual dysfunctions were met by over $1 / 3$ of respondents in their postmenopausal period.

The placement of the sexual sphere in one's own value hierarchy can differ depending on a given person, yet generally it is considered an important aspect of life, also among people at more advanced ages. A research conducted on a population of over 1600 women and men of over 45 years of age confirmed that for $55-60 \%$ Americans sexual activity is an important element of a satisfying relationship and quality of life of elderly persons [17]. Disorders in the sexual sphere are, in turn, unequivocally identified with a sense of discomfort. 
Due to the fact that in the authors' own research all the analysed variables (connected with one's physical and psychological wellbeing as well as behaviour) proved to significantly differentiate between women with and without dysfunctions, it can be concluded that this type of problems has a significant influence on the overall quality of life. The existence of such a relationship in a group of postmenopausal women was proven by a research conducted by Nazarpour and co-researchers. Using the Female Sexual Function Index (FSFI) and the WHO Quality of Life-BREF (WHOQOL-BREF), they demonstrated a positive relationship between the overall sexual functioning and the overall quality of life as well as with all the analysed domains of quality of life: physical health, psychological, social relationships, environment [18]. In turn, Show-Riu and co-researchers, in a cross-functional research conducted on a group of over 1000 middle-aged women, confirmed the relationship between the occurrence of sexual dysfunctions and the health-related quality of life [19]. The respondents without sexual dysfunctions were characterised by lower intensity of menopausal and depressive symptoms, whereas, on the other hand, higher efficiency of sexual functions, such as Desire, Arousal, Lubrication, Orgasm, Satisfaction, lack of Pain. Moreover, they presented more health-promoting behaviours connected with nutrition, health prophylaxis and health practices (e.g. sleep and rest, body weight control, adherence to doctor's recommendations) as well as a positive psychological attitude. They had also better body self-esteem within the scope of sense of sexual attractiveness and physical fitness, yet they demonstrated more behaviours connected with concern about their body weight. It is insomuch interesting as this variable proved to be at the same time one of the risk factors of sexual dysfunctions.

In order to understand this seemingly inconsistent phenomenon, we can use the fact that the respondents without sexual dysfunctions, despite greater concern about their weight, did in fact weigh significantly less than the respondents with dysfunctions, had a significantly lower BMI and better health self-assessment. Dissatisfaction with one's own weight and concern about its increase are presented by a large number of women, regardless of their current body weight, and BMI has a stronger influence on their overall body self-image than in the case of men [20]. Therefore, it can be suspected that body weight is an especially delicate aspect also in the life of postmenopausal women and constitutes a factor mediating between the concern about one's weight and the occurrence of dysfunctions in sexual life. This hypothesis, however, would require confirmation in the course of more advanced analyses, whose lack can be considered one of the limitations of the present research. The other ones are connected with the non-inclusion in the research of such significant variables as the objective state of health (e.g. the kind and duration of chronic diseases, taken medications, past gynaecological surgeries), history of possible treatment of sexual dysfunctions or the quality of partner relationships.

Lack of partner proved to be the strongest risk factor of sexual dysfunctions. Other authors confirm that the distress connected with sexuality concerns not only women living in relationships, but also those that currently do not have a partner and are sexually inactive [21]. Having close relationships with other people, not only those of sexual nature, has a beneficial influence on physical and psychological health of every person, since it is the source of social support [22].

Among all the diagnosed risk factors of sexual dysfunctions in women in the postmenopausal period only age is a non-modifiable variable. The other ones are subject to external influences and that is why they should be taken into account while planning health policies and implementing support programmes for women at this stage of life. General gynaecological care can, for example, contribute to the alleviation of symptoms of menopause, not only by giving women access to hormone replacement therapy, but also by education concerning health-promoting lifestyle. It seems that a special place in prophylaxis and health promotion should fall to questions connected with maintaining correct body weight, which is crucial not only in the context of physical and psychological health, but also has a significant influence on the sense of women's sexual attractiveness as well as on formation and maintenance of sexual relations.

\section{CONCLUSIONS}

There is a relation between the occurrence of sexual dysfunctions and the intensity of menopausal symptoms, efficiency of determined sexual functions, level of depression, body self-esteem and health behaviours of women in the postmenopausal period. Crucial risk factors of sexual dysfunctions in this group include: age, relationship status, intensity of menopausal symptoms, sense of sexual attractiveness and concern about body weight.

\section{REFERENCES}

1. McCabe MP, Sharlip ID, Atalla E, et al. Definitions of Sexual Dysfunctions in Women and Men: A Consensus Statement From the Fourth International Consultation on Sexual Medicine 2015. J Sex Med. 2016; 13(2): 135-143, doi: 10.1016/j.jsxm.2015.12.019, indexed in Pubmed: 26953828.

2. Nicolosi A, Laumann EO, Glasser DB, et al. Global Study of Sexual Attitudes and Behaviors Investigators' Group. Sexual behavior and sexual dysfunctions after age 40: the global study of sexual attitudes and behaviors. Urology. 2004; 64(5): 991-997, doi: 10.1016/j.urology.2004.06.055, indexed in Pubmed: 15533492.

3. Eftekhar T, Dashti M, Shariat M, et al. Female Sexual Function During the Menopausal Transition in a Group of Iranian Women. J Family Reprod Health. 2016; 10(2): 52-58, indexed in Pubmed: 27648093.

4. Ornat L, Martínez-Dearth R, Muñoz A, et al. Sexual function, satisfaction with life and menopausal symptoms in middle-aged women. Maturitas. 2013; 75(3): 261-269, doi: 10.1016/j.maturitas.2013.04.007, indexed in Pubmed: 23684086. 
5. Nappi RE, Wawra K, Schmitt S. Hypoactive sexual desire disorder in postmenopausal women. Gynecol Endocrinol. 2006; 22(6): 318-323, doi: 10.1080/09513590600762265, indexed in Pubmed: 16785156.

6. Przybylski M, Spaczyński M. [Hypoactive sexual desire disorder]. Ginekol Pol. 2009; 80(7): 518-522, indexed in Pubmed: 19697816.

7. Szpak R, Folwarczny W, Drozdzol A, et al. [Partner relationships in menopausal period]. Ginekol Pol. 2010; 81(2): 115-119, indexed in Pubmed: 20232709.

8. Nazarpour S, Simbar M, Tehrani FR. Factors affecting sexual function in menopause: A review article. Taiwan J Obstet Gynecol. 2016; 55(4): 480-487, doi: 10.1016/j.tjog.2016.06.001, indexed in Pubmed: 27590367.

9. Afshari P, Houshyar Z, Javadifar N, et al. The Relationship Between Body Image and Sexual Function in Middle-Aged Women. Electron Physician. 2016; 8(11): 3302-3308, doi: 10.19082/3302, indexed in Pubmed: 28070265.

10. Heidari M, Ghodusi M, Rezaei P, et al. Sexual Function and Factors Affecting Menopause: A Systematic Review. J Menopausal Med. 2019; 25(1): 15-27, doi: 10.6118/jmm.2019.25.1.15, indexed in Pubmed: 31080785.

11. Elavsky S, McAuley E. Physical activity and mental health outcomes during menopause: a randomized controlled trial. Ann Behav Med. 2007; 33(2): 132-142, doi: 10.1007/bf02879894, indexed in Pubmed: 17447865.

12. Bosworth HB, Bastian LA, Kuchibhatla MN, et al. Depressive symptoms, menopausal status, and climacteric symptoms in women at midlife. Psychosom Med. 2001; 63(4): 603-608, doi: 10.1097/00006842-20010700000013, indexed in Pubmed: 11485114.

13. Jackson KL, Janssen I, Appelhans BM, et al. Body image satisfaction and depression in midlife women: the Study of Women's Health Across the Nation (SWAN). Arch Womens Ment Health. 2014; 17(3): 177-187, doi: 10.1007/s00737-014-0416-9, indexed in Pubmed: 24623160.

14. Kilpela LS, Becker CB, Wesley N, et al. Body Image in Adult Women: Moving Beyond the Younger Years. Adv Eat Disord. 2015; 3(2): 144-164, doi: 10.1080/21662630.2015.1012728, indexed in Pubmed: 26052476.
15. Smith RL, Gallicchio L, Flaws JA. Factors Affecting Sexual Function in Midlife Women: Results from the Midlife Women's Health Study. JWomens Health (Larchmt). 2017; 26(9): 923-932, doi: 10.1089/jwh.2016.6135, indexed in Pubmed: 28437219.

16. Portman DJ, Gass MLS. Vulvovaginal Atrophy Terminology Consensus Conference Panel. Genitourinary syndrome of menopause: new terminology for vulvovaginal atrophy from the International Society for the Study of Women's Sexual Health and the North American Menopause Society. J Sex Med. 2014; 11(12): 2865-2872, doi: 10.1111/jsm.12686, indexed in Pubmed: 25155380.

17. American Association of Retired Persons (AARP). Sexuality at midlife and beyond: 2004 Update of attitudes and behaviors. www.aarp.org (2005). http://assets.aarp.org/rgcenter/general/2004_sexuality.pdf.

18. Nazarpour S, Simbar M, Ramezani Tehrani F, et al. Quality of life and sexual function in postmenopausal women. J Women Aging. 2018; 30(4): 299-309, doi: 10.1080/08952841.2017.1395539, indexed in Pubmed: 29077541.

19. Chang SR, Yang CF, Chen KH. Relationships between body image, sexual dysfunction, and health-related quality of life among middle-aged women: A cross-sectional study. Maturitas. 2019; 126: 45-50, doi: 10.1016/j. maturitas.2019.04.218, indexed in Pubmed: 31239117.

20. Algars $M$, Santtila $P$, Varjonen $M$, et al. The adult body: how age, gender, and body mass index are related to body image. J Aging Health 2009; 21(8): 1112-1132, doi: 10.1177/0898264309348023, indexed in Pubmed: 19897779.

21. Worsley R, Bell RJ, Gartoulla P, et al. Prevalence and Predictors of Low Sexual Desire, Sexually Related Personal Distress, and Hypoactive Sexual Desire Dysfunction in a Community-Based Sample of Midlife Women. J Sex Med. 2017; 14(5): 675-686, doi: 10.1016/j.jsxm.2017.03.254, indexed in Pubmed: 28499520.

22. Umberson $D$, Montez JK. Social relationships and health: a flashpoint for health policy. J Health Soc Behav. 2010; 51 Suppl: S54-S66, doi: 10.1177/0022146510383501, indexed in Pubmed: 20943583. 